\title{
Predictors of Fecal Incontinence and Related Quality of Life After a Total Mesorectal Excision With Primary Anastomosis for Patients With Rectal Cancer
}

\author{
Marieke S. Walma, Verena N. N. Kornmann, Djamila Boerma, Marnix A. J. de Roos ${ }^{1}$, Henderik L. van Westreenen \\ Department of Surgery, St. Antonius Hospital, Nieuwegein, ${ }^{1}$ Department of Surgery, Rivierenland Hospital, Tiel, The Netherlands
}

Purpose: After total mesorectal excision (TME) with primary anastomosis for patients with rectal cancer, the quality of life (QoL) may be decreased due to fecal incontinence. This study aimed to identify predictors of fecal incontinence and related QoL.

Methods: Patients who underwent TME with primary anastomosis for rectal cancer between December 2008 and June 2012 completed the fecal incontinence quality of life scale (FIQoL) and Wexner incontinence score. Factors associated with these scores were identified using a linear regression analysis.

Results: A total of 80 patients were included. Multivariate analysis identified a diverting ileostomy $(n=58)$ as an independent predictor of an unfavorable outcome on the FIQoL subscale coping/behavior $(\mathrm{P}=0.041)$. Ileostomy closure within and after 3 months resulted in median Wexner scores of 5.0 (interquartile range [IQR], 2.5-8.0) and 10.5 (IQR, 6.0-13.8), respectively $(\mathrm{P}<0.001)$. The median FIQoL score was 15.0 (IQR, 13.1-16.0) for stoma closure within 3 months versus 12.0 (IQR, 10.5-13.9) for closure after 3 months $(\mathrm{P}=0.001)$.

Conclusion: A diverting ileostomy is a predictor for an impaired FIQoL after a TME for rectal cancer. Stoma reversal within 3 months showed better outcomes than reversal after 3 months. Patients with a diverting ileostomy should be informed about the impaired QoL, even after stoma closure.

Keywords: Rectal neoplasms; Quality of life; Fecal incontinence; Ileostomy

\section{INTRODUCTION}

A total mesorectal excision (TME) is the surgery of choice for patients with rectal cancer. Preferably a sphincter-saving procedure is advocated [1]. Oncological results are comparable to those for the formerly-preferred abdominoperineal resection (APR) [2]. The reason for sphincter preservation is the supposed better quality of life (QoL) compared with the QoL for patients with a per-

Received: November 11, 2014 - Accepted: January 28, 2015

Correspondence to: Marieke S. Walma, M.D.

Department of Surgery, University Medical Centre, Utrecht Postbus 85500,

3508 GA Utrecht, The Netherlands

Tel: +31-0-30-75-56968, Fax: +31-0-30-75-55459

E-mail:mariekewalma@gmail.com

(c) 2015 The Korean Society of Coloproctology

This is an open-access article distributed under the terms of the Creative Commons Attribution NonCommercial License (http://creativecommons.org/licenses/by-nc/3.0) which permits unrestricted non-

commercial use, distribution, and reproduction in any medium, provided the original work is properly cited. manent stoma after APR. Although sphincter preserving surgery has become the surgery of choice for treating patients with rectal cancer, a recent review demonstrated that up to $90 \%$ of the patients developed changes in bowel habit, including fecal incontinence [3]. This may negatively influence the QoL. A meta-analysis demonstrated comparable general QoL for both the low anterior resection and the APR [4], but individual domains of QoL scores showed inconclusive results $[4,5]$. Different causal mechanisms of the decreased bowel function after sphincter-saving surgery have been investigated. The definitive cause still remains unresolved and seems to be multifactorial [3]. This study aims to identify predicting factors for fecal incontinence and related QoL after sphincter-saving surgery for the treatment of rectal cancer.

\section{METHODS}

Patients that had TME surgery for rectal cancer from December 2008 until June 2012 by using sphincter preservation with a pri- 
mary anastomosis were included. Patients were treated in two hospitals: a teaching hospital (St. Antonius Hospital, Nieuwegein, The Netherlands) and a district hospital (Rivierenland Hospital, Tiel, The Netherlands). The patients' characteristics were retrospectively collected from their charts. A rectal tumor was defined as a tumor below an imaginary line from the upper part of the pubic symphysis and the promontory on sagittal reconstructions of the pelvic magnetic resonance imaging (MRI) scan. In the case of sigmoidoscopy, the definition of a tumor less than $15 \mathrm{~cm}$ from the anal verge was used. Comorbidity was scored using the ageadjusted Charlson comorbidity index (CCI) and the International Classification of Diseases, 10 th revision, for diagnosis coding [6, 7]. Patients were subdivided into low $(\leq 5 \mathrm{~cm})$, mid $(>5 \mathrm{~cm}, \leq 10 \mathrm{~cm})$ or high $(>10 \mathrm{~cm}, \leq 15 \mathrm{~cm})$ rectal tumor groups based upon MRI. The sigmoidoscopy report was used when the distance of the tumor to the anal verge was missing from the MRI report. Preoperative therapy was either short-course radiotherapy $(5 \times 5$ Gray $)$ or a combination of long-course radiotherapy $(25 \times 2$ Gray $)$ with chemotherapy. One center treated all patients with perioperative pelvic floor muscle training (PFMT), which consisted of at least four consultations with a specialized physiotherapist.

Complications were measured during the first 30 days following surgery. An anastomotic leakage was defined as the presence of leakage or a presacral abscess on an abdominal computed tomography-scan with oral, rectal, and intravenous contrast. A stoma-related complication included a high output stoma, a prolapse of the small bowel, necrosis, or a nonproducing stoma because of stenosis. The surgery was executed according to the TME technique by using laparoscopy or laparotomy. High ligation of the mesenteric inferior vessels and mobilization of the splenic flexure were performed. Dissection of the rectum was carried to the pelvic floor with nerve preservation. Reconstruction was a side-to-end stapled colorectal anastomosis. Possible predictors that were tested were age, gender, body mass index, CCI, distance of the tumor to the anal verge, perioperative PFMT, preoperative treatment, a diverting (ileo)stomy, blood loss, duration of surgery, anastomotic leakage, stoma-related complications, reoperation, tumor stage, and time interval to completion of the questionnaire.

Fecal incontinence and the QoL outcomes were measured using the validated fecal incontinence quality of life scale (FIQoL) and the Wexner incontinence score, both adapted to the Dutch language $[8,9]$. FIQoL includes four different subscales: lifestyle, coping/behavior, depression/self-perception and embarrassment. The total FIQoL score is the sum of all four subscales. Subscale scores range from 1 to 5 and are the average response to all items on the scale. A lower score indicates a lower functional status and related quality of life [8]. A higher Wexner score indicates more symptoms of fecal incontinence on a scale from 0 to 20 [9].

One researcher (M.S.W.) contacted eligible patients to ask then to voluntarily participate in the study. Self-administered questionnaires were sent to patients by e-mail or letter. Phone-call reminders were made to nonresponders. Patients with a diverting stoma in situ at the time of answering the questionnaire were excluded from the analysis. The time interval to completing of the questionnaire was measured from the day of restored bowel continuity until the day of answering the questionnaire.

The data were analyzed using IBM SPSS Statistics ver. 20.0 (IBM Co., Armonk, NY, USA). A statistician was asked for advice concerning the analysis. The values of the patients' characteristics are given as a median and IQR for all continuous data. Values of binomial data are shown as a number of patients and percent of group. The relationship between possible predictors and outcome was analyzed using a univariate linear regression analysis. Variables associated with our outcomes $(\mathrm{P}<0.100)$ were entered into a multivariate linear regression analysis. Differences between groups were tested using the independent two-sample t-test within normally distributed data and the Mann-Whitney U-test within nonnormally distributed data. Normality was tested by using the Kolmogorov-Smirnov test. The chi-square test was used to compare categorical variables between groups. A value of $\mathrm{P}<0.05$ was used as the level of significance.

\section{RESULTS}

During this study period, TME was performed on 138 patients at the two participating hospitals. A total of 99 patients were contacted. The remaining 39 patients were excluded from this study due to death during follow-up $(\mathrm{n}=14)$, a stoma in situ $(\mathrm{n}=19)$, creation of an end colostomy $(n=2)$, or loss to follow-up $(n=4)$. Finally, $80.8 \%(n=80)$ of the contacted patients responded and were included.

The patients' characteristics are summarized in Table 1 . The median age of the included patients at the time of surgery was 63 years (IQR, 57-69 years), and 66.3\% $(n=53)$ were male. Patients predominantly had midrectal tumors $(n=42,52.5 \%)$ with a median distance of the tumor from the anal verge of $9.0 \mathrm{~cm}$ (IQR, $6.0-12.0 \mathrm{~cm}$ ). The median time interval to completion of the questionnaire was 19 months (IQR, 10-29 months). Five patients (6.3\%) had an anastomotic leak as a complication. Four of them received a diverting ileostomy at the primary surgery, and the other received a diverting ileostomy after having been diagnosed with this complication.

The median Wexner score was 7.0 (IQR, 4.0-12.0) (Table 2). Five predicting factors for a higher Wexner score (unfavorable outcome) were identified in the univariate analysis: perioperative PFMT, preoperative therapy, a diverting ileostomy, longer duration of surgery, and a stoma-related complication. In the multivariate regression analysis, none of these factors was independently associated with a higher Wexner score (data not shown).

The median FIQoL scores are depicted in Table 2. In the univariate analysis, four variables had a relationship with the FIQoL subscale coping/behavior: preoperative therapy, a diverting ileostomy, an anastomotic leak, and a stoma-related complication. Multivariate regression analysis revealed a diverting ileostomy (B 
Table 1. Patients' characteristics $(n=80)$

\begin{tabular}{|c|c|}
\hline Characteristic & Value \\
\hline Age (yr) & $63(57-69)$ \\
\hline \multicolumn{2}{|l|}{ Gender } \\
\hline Male/female & $53(66.3) / 27(33.8)$ \\
\hline Body mass index $\left(\mathrm{kg} / \mathrm{m}^{2}\right)$ & $26.3(23.8-28.7)$ \\
\hline Charlson comorbidity index & $4(4-6)$ \\
\hline \multicolumn{2}{|l|}{ TNM stage (UICC) } \\
\hline 1 & $26(32.5)$ \\
\hline$\|$ & $18(22.5)$ \\
\hline III & $33(41.3)$ \\
\hline IV & $3(3.8)$ \\
\hline Distance of the tumor from anal verge $(\mathrm{cm})$ & $9.0(6.0-12.0)$ \\
\hline$\leq 5$ & $9(11.3)$ \\
\hline$>5, \leq 10$ & $42(52.5)$ \\
\hline$>10, \leq 15$ & $29(36.3)$ \\
\hline Perioperative PFMT & $32(40.0)$ \\
\hline Preoperative therapy & $62(77.5)$ \\
\hline Short-course radiotherapy & $46(57.5)$ \\
\hline Long-course radiochemotherapy & $16(20.0)$ \\
\hline \multicolumn{2}{|l|}{ Operative characteristic } \\
\hline \multicolumn{2}{|l|}{ Approach } \\
\hline Laparoscopy & $66(82.5)$ \\
\hline Laparotomy & $11(13.8)$ \\
\hline Conversion & $3(3.8)$ \\
\hline \multicolumn{2}{|l|}{ Additional procedures } \\
\hline Diverting ileostomy & $58(72.5)$ \\
\hline Diverting colostomy & $3(3.8)$ \\
\hline Blood loss (mL) ${ }^{\mathrm{a}}$ & $100(30-350)$ \\
\hline Duration of surgery (min) & $163(123-240)$ \\
\hline \multicolumn{2}{|l|}{ Postoperative characteristic } \\
\hline Length of hospital stay (day) & $6(5-10)$ \\
\hline \multicolumn{2}{|l|}{ Complication } \\
\hline Anastomotic leak & $5(6.3)$ \\
\hline Stoma-related complication & $9(11.3)$ \\
\hline Reoperation & $7(8.8)$ \\
\hline Time interval to completing the questionnaire (mo) & $19(10-29)$ \\
\hline
\end{tabular}

Values are presented as median (interquartile range) or number of patients (\%). UICC, Union for International Cancer Control; PFMT, pelvic floor muscle training. aData add up to 75 because of occasional missing data.

$=-0.524 ; 95 \% \mathrm{CI},-1.072$ to $-0.021 ; \mathrm{P}=0.041)$ as an independent predictor of an unfavorable outcome (Table 3 ). In the univariate analysis, a variety of predictors were identified for an unfavorable outcome of other FIQoL subscale scores. Multivariate analysis of
Table 2. Wexner and FIQoL scores $(n=80)$

\begin{tabular}{lc}
\hline Score & Median (IQR) \\
\hline Wexner score & $7.0(4.0-12.0)$ \\
FIQoL score & \\
FIQoL total & $13.4(11.4-15.7)$ \\
FIQoL lifestyle & $3.5(3.0-4.0)$ \\
FIQoL coping/behavior & $2.9(2.4-3.7)$ \\
FIQoL depression/self-perception & $3.9(3.3-4.3)$ \\
FIQoL embarrassment & $3.5(3.0-4.0)$ \\
\hline
\end{tabular}

$\mathrm{FIQoL}$, fecal incontinence quality of life scale; IQR, interquartile range.

Table 3. Multivariate linear regression analysis: FIQoL

\begin{tabular}{lll}
\hline FIQoL coping/behavior & \multicolumn{1}{c}{ B (95\% Cl) } & P-value \\
\hline Preoperative therapy (yes) & $-0.043(-0.572$ to 0.487$)$ & 0.872 \\
Diverting ileostomy (yes) & $-0.524(-1.072$ to -0.021$)$ & 0.041 \\
Complication: anastomotic leak (yes) & $-0.689(-1.407$ to 0.028$)$ & 0.06 \\
Stoma-related complication (yes) & $-0.318(-0.883$ to 0.248$)$ & 0.266 \\
\hline
\end{tabular}

$\mathrm{FIQL}$, fecal incontinence quality of life scale; $\mathrm{B}$, regression coefficient; $\mathrm{Cl}$, confidence interval.

FIQoL lifestyle, FIQoL embarrassment, FIQoL depression/selfperception, or FIQoL total score did not show independently associated factors with our outcome.

Of 80 patients, 58 (72.5\%) received a diverting ileostomy at primary surgery and underwent restoration of bowel continuity. The characteristics of these patients are summarized in Table 4. In 17 patients (29.3\%), bowel continuity was restored within 3 months following TME, compared with 41 patients $(70.7 \%)$ in whom bowel continuity was restored 3 months or longer after TME. Only the length of hospital stay differed between these groups. Patients with stoma closure within 3 months had a median length of hospital stay of 6 days (IQR, 5-8 days) compared to 8 days (IQR, 6-19 days) for patients with stoma closure after 3 months (P $=0.009$ ). This was not due to comorbidity or postoperative complications as no differences were found between groups concerning these variables (Table 4). Patients in whom bowel continuity was restored within and after 3 months had median Wexner scores of 5.0 (IQR, 2.5-8.0) versus 10.5 (IQR: 6.0-13.8), respectively $(\mathrm{P}<0.001)$. Furthermore, the FIQoL total score was significantly more favorable for patients who had their stoma closed within 3 months compared to those who had their stoma closed after 3 months (median, 15.0; IQR, 13.1-16.0 vs. median, 12.0; IQR, 10.5-13.9, respectively, $\mathrm{P}=0.001$ ) (Table 5).

\section{DISCUSSION}

First sentence of Discussion: maybe change to: "In this study, a temporary ileostomy independently predicted impaired FIQoL concering coping and behavior, after stoma closure, in patients 
Table 4. Patients with a diverting ileostomy

\begin{tabular}{|c|c|c|c|c|}
\hline \multirow{2}{*}{ Characteristic } & \multirow{2}{*}{ All patients $(n=58)$} & \multicolumn{2}{|c|}{ Stoma in situ } & \multirow{2}{*}{ P-value } \\
\hline & & $\leq 3$ Months $(n=17)$ & $>3$ Months $(n=41)$ & \\
\hline Age (yr) & $63(54-70)$ & $64(53-70)$ & $63(56-70)$ & 0.778 \\
\hline \multicolumn{5}{|l|}{ Gender } \\
\hline Male/female & $40(69.0) / 18(31.0)$ & $14(82.4) / 3(17.6)$ & $26(63.4) / 15(36.6)$ & 0.268 \\
\hline Body mass index $\left(\mathrm{kg} / \mathrm{m}^{2}\right)$ & $26.0(23.6-29.1)$ & $26.6(24.7-29.4)$ & $25.8(23.2-28.6)$ & 0.488 \\
\hline Charlson comorbidity index & $4(3-5)$ & $4(3-6)$ & $4(4-6)$ & 0.398 \\
\hline \multicolumn{5}{|l|}{ TNM stage (UICC) } \\
\hline I & $21(36.2)$ & $9(52.9)$ & $12(29.3)$ & 0.159 \\
\hline$\|$ & $13(22.4)$ & $3(17.6)$ & $10(24.4)$ & 0.83 \\
\hline III & $24(41.4)$ & $5(29.4)$ & $19(46.3)$ & 0.369 \\
\hline Distance of the tumor from anal verge $(\mathrm{cm})$ & $8.0(5.9-11.3)$ & $9.0(7.0-11.5)$ & $8.0(5.5-11.5)$ & 0.321 \\
\hline$\leq 5$ & $9(15.5)$ & $1(5.9)$ & $8(19.5)$ & 0.365 \\
\hline$>5, \leq 10$ & $31(53.4)$ & $11(64.7)$ & $20(48.8)$ & 0.414 \\
\hline$>10, \leq 15$ & $18(31.0)$ & $5(29.4)$ & $13(31.7)$ & 1 \\
\hline Perioperative PFMT & $30(51.7)$ & $8(47.1)$ & $22(53.7)$ & 0.866 \\
\hline Preoperative therapy & $54(93.1)$ & $17(100.0)$ & $37(90.2)$ & 0.31 \\
\hline Short-course radiotherapy & $41(70.7)$ & 15 (88.2) & $26(63.4)$ & 0.116 \\
\hline Long-course radiochemotherapy & $13(22.4)$ & $2(11.8)$ & $11(26.8)$ & 0.365 \\
\hline \multicolumn{5}{|l|}{ Operative characteristic } \\
\hline \multicolumn{5}{|l|}{ Approach } \\
\hline Laparoscopy & $47(81.0)$ & 15 (88.2) & $32(78.0)$ & 0.594 \\
\hline Laparotomy & $9(15.5)$ & $2(11.8)$ & $7(17.1)$ & 0.912 \\
\hline Conversion & $2(3.4)$ & $0(0.0)$ & $2(4.9)$ & 1 \\
\hline Blood loss (mL) ${ }^{\mathrm{a}}$ & $150(50-400)$ & $100(35-388)$ & $200(50-500)$ & 0.241 \\
\hline Duration of surgery (min) & $180(149-258)$ & $155(120-219)$ & $190(150-278)$ & 0.087 \\
\hline \multicolumn{5}{|l|}{ Postoperative characteristic } \\
\hline Length of hospital stay (day) & $7(5-14)$ & $6(5-8)$ & $8(6-19)$ & 0.009 \\
\hline \multicolumn{5}{|l|}{ Complication } \\
\hline Anastomotic leak & $4(6.9)$ & $1(5.9)$ & $3(7.3)$ & 1 \\
\hline Stoma-related complication & $9(15.5)$ & $3(17.6)$ & $6(14.6)$ & 1 \\
\hline Reoperation & $6(10.3)$ & $2(11.8)$ & $4(9.8)$ & 1 \\
\hline Time interval for completing the questionnaire (mo) & $19(10-28)$ & $14(10-24)$ & $19(12-29)$ & 0.345 \\
\hline
\end{tabular}

Values are presented as median (interquartile range) or number of patients (\%).

UICC, Union for International Cancer Control; PFMT, pelvic floor muscle training.

treated with a TME for rectal cancer. This means that patients stay near a restroom, worry about being at a toilet in time, feel like they have no control over their bowels, and have less sex than they would like to have. In addition, patients with stoma reversal within 3 months showed better functional outcome and related QoL. All other variables associated with the Wexner and the FIQoL scores in the univariate analysis were shown not to be independent predictors in the multivariate analysis. To our knowl- edge, the negative value of a temporary ileostomy on the FIQoL after stoma closure has never been described. Four studies investigated a diverting ileostomy as a possible predictor for impaired functional outcome, but none of the results reached significance [10-13]. Several studies showed an impaired functional outcome after TME in patients who had a low anastomosis and patients who had preoperative radiotherapy, but our study did not reveal these items as risk factors [11-16]. Anastomotic leakage negatively 
Table 5. Patients with a diverting ileostomy: Wexner and FIQoL scores

\begin{tabular}{|c|c|c|c|}
\hline \multirow{2}{*}{ Score } & \multicolumn{2}{|c|}{ Stoma in situ } & \multirow{2}{*}{ P-value } \\
\hline & $\leq 3$ Months $(n=17)$ & $>3$ Months $(n=41)$ & \\
\hline Wexner score & $5.0(2.5-8.0)$ & $10.5(6.0-13.8)$ & $<0.001$ \\
\hline \multicolumn{4}{|l|}{ FIQoL score } \\
\hline FIQoL total & $15.0(13.1-16.0)$ & $12.0(10.5-13.9)$ & 0.001 \\
\hline FIQoL lifestyle & $3.8(3.4-4.0)$ & $3.0(2.2-3.6)$ & $<0.001$ \\
\hline FIQoL coping/behavior & $3.2(2.7-3.6)$ & $2.5(2.1-3.0)$ & 0.011 \\
\hline $\begin{array}{l}\text { FIQOL depression/ } \\
\text { self-perception }\end{array}$ & $4.1(3.8-4.4)$ & $3.4(2.8-4.1)$ & 0.001 \\
\hline FIQoL embarrassment & $3.7(3.3-4.0)$ & $3.3(2.7-3.7)$ & 0.018 \\
\hline
\end{tabular}

Values are presented as median (interquartile range).

FIQDL, fecal incontinence quality of life scale.

affected FIQoL or bowel function in one study [12], but this association was not found in several other studies $[10,11,13,14,17$, 18]. Lange et al. [11] identified height of tumor and excessive blood loss as predictors of fecal incontinence, but only in patients who received preoperative radiotherapy. Furthermore, age [13], gender [14], and operative blood loss [13] had a relationship with bowel function following TME in other studies.

The presence of a temporary ileostomy significantly reduces the QoL of patients $[19,20]$. Also, with a temporary stoma, there is the need for a second operation, which has additional morbidity [21]. Furthermore, our study shows that a temporary ileostomy impairs FIQoL even after stoma closure. Risks of developing an anastomotic leakage and of having to undergo related reoperations increase if a stoma is omitted at primary surgery [22, 23]. Therefore, we cannot advocate the omission of a temporary ileostomy. Still, patients should be informed about the impact of an ileostomy on QoL even after stoma closure, and a permanent colostomy should be considered. When a temporary ileostomy is performed, stoma reversal should be done within 3 months after the TME. The exact reason for a better outcome after early stoma reversal cannot be given. In The Netherlands, stoma reversal after 3 months is not rare. Also, our comparison of patients with different timings of stoma reversal did not show any differences concerning complication rate, comorbidity, tumor height, or tumor stage. Therefore, our outcome does not seem to have been confounded. The long diversion of a colorectal anastomosis is supposed to reduce the functional adaptability of the neorectum. This might be the etiology of more fecal incontinence after stoma reversal.

Our study has some limitations due its retrospective design. Furthermore, patients were recruited from two hospitals with some differences in the protocols. Patients in whom bowel continuity was not restored were excluded for analysis because they were not able to answer questions concerning fecal incontinence. This could have led to selection bias for those patients with anastomotic-related complications. Another limitation is that a preoperative measurement of QoL is missing, and we did not analyze nonre- sponders. Lastly, the small numbers of anastomotic leakage made our attempt to correct for this parameter in the multivariate analysis difficult. Therefore, this might still be a confounding factor when measuring FIQoL. Baxter et al. [24] states that the perception of the patient must be the foundation of any evaluation of incontinence or the impact of incontinence. Objective measurements for bowel function have been used, but were shown to have low specificity and sensitivity [24]. Therefore, the use of questionnaires is a well-considered decision. The FIQoL and the Wexner incontinence score are the questionnaires that are most suitable for evaluating the QoL and for assessing severity, respectively [25]. The questionnaires were self-administered; consequently, the potential for socially desirable answers was minimized.

In conclusion, a diverting ileostomy is a predictor for an impaired FIQoL after a TME for treating rectal cancer. Stoma reversal within 3 months showed a better functional outcome compared with ileostomy closure after 3 months. This might be due to a reduced functional adaptability of the neorectum after diversion. Patients with a temporary ileostomy should be informed preoperatively about the impaired QoL, even after stoma closure.

\section{CONFLICT OF INTEREST}

No potential conflict of interest relevant to this article was reported.

\section{REFERENCES}

1. Lange MM, Rutten HJ, van de Velde CJ. One hundred years of curative surgery for rectal cancer: 1908-2008. Eur J Surg Oncol 2009;35:456-63.

2. Di Betta E, D'Hoore A, Filez L, Penninckx F. Sphincter saving rectum resection is the standard procedure for low rectal cancer. Int J Colorectal Dis 2003;18:463-9.

3. Bryant CL, Lunniss PJ, Knowles CH, Thaha MA, Chan CL. Anterior resection syndrome. Lancet Oncol 2012;13:e403-8.

4. Cornish JA, Tilney HS, Heriot AG, Lavery IC, Fazio VW, Tekkis PP. A meta-analysis of quality of life for abdominoperineal excision of rectum versus anterior resection for rectal cancer. Ann Surg Oncol 2007;14:2056-68.

5. Pachler J, Wille-Jorgensen P. Quality of life after rectal resection for cancer, with or without permanent colostomy. Cochrane Database Syst Rev 2005;(2):CD004323.

6. Charlson ME, Pompei P, Ales KL, MacKenzie CR. A new method of classifying prognostic comorbidity in longitudinal studies: development and validation. J Chronic Dis 1987;40:373-83.

7. Sundararajan V, Henderson T, Perry C, Muggivan A, Quan H, Ghali WA. New ICD-10 version of the Charlson comorbidity index predicted in-hospital mortality. J Clin Epidemiol 2004;57: 1288-94.

8. Rockwood TH, Church JM, Fleshman JW, Kane RL, Mavrantonis C, Thorson AG, et al. Fecal incontinence quality of life scale: qual- 
ity of life instrument for patients with fecal incontinence. Dis Colon Rectum 2000;43:9-16.

9. Vaizey CJ, Carapeti E, Cahill JA, Kamm MA. Prospective comparison of faecal incontinence grading systems. Gut 1999;44:77-80.

10. Lindgren R, Hallbook O, Rutegard J, Sjodahl R, Matthiessen P. Does a defunctioning stoma affect anorectal function after low rectal resection? Results of a randomized multicenter trial. Dis Colon Rectum 2011;54:747-52.

11. Lange MM, den Dulk M, Bossema ER, Maas CP, Peeters KC, Rutten HJ, et al. Risk factors for faecal incontinence after rectal cancer treatment. Br J Surg 2007;94:1278-84.

12. Welsh FK, McFall M, Mitchell G, Miles WF, Woods WG. Pre-operative short-course radiotherapy is associated with faecal incontinence after anterior resection. Colorectal Dis 2003;5:563-8.

13. Graf W, Ekstrom K, Glimelius B, Pahlman L. A pilot study of factors influencing bowel function after colorectal anastomosis. Dis Colon Rectum 1996;39:744-9.

14. Dahlberg M, Glimelius B, Graf W, Pahlman L. Preoperative irradiation affects functional results after surgery for rectal cancer: results from a randomized study. Dis Colon Rectum 1998;41:543-9.

15. Pollack J, Holm T, Cedermark B, Holmstrom B, Mellgren A. Long-term effect of preoperative radiation therapy on anorectal function. Dis Colon Rectum 2006;49:345-52.

16. Peeters KC, van de Velde CJ, Leer JW, Martijn H, Junggeburt JM, Kranenbarg EK, et al. Late side effects of short-course preoperative radiotherapy combined with total mesorectal excision for rectal cancer: increased bowel dysfunction in irradiated patients: a Dutch colorectal cancer group study. J Clin Oncol 2005;23:6199-206.

17. Riss S, Stremitzer S, Riss K, Mittlbock M, Bergmann M, Stift A.
Pelvic organ function and quality of life after anastomotic leakage following rectal cancer surgery. Wien Klin Wochenschr 2011;123: 53-7.

18. Bittorf B, Stadelmaier U, Merkel S, Hohenberger W, Matzel KE. Does anastomotic leakage affect functional outcome after rectal resection for cancer? Langenbecks Arch Surg 2003;387:406-10.

19. Tsunoda A, Tsunoda Y, Narita K, Watanabe M, Nakao K, Kusano M. Quality of life after low anterior resection and temporary loop ileostomy. Dis Colon Rectum 2008;51:218-22.

20. O'Leary DP, Fide CJ, Foy C, Lucarotti ME. Quality of life after low anterior resection with total mesorectal excision and temporary loop ileostomy for rectal carcinoma. Br J Surg 2001;88:1216-20.

21. van Westreenen HL, Visser A, Tanis PJ, Bemelman WA. Morbidity related to defunctioning ileostomy closure after ileal pouch-anal anastomosis and low colonic anastomosis. Int J Colorectal Dis 2012;27:49-54.

22. Huser N, Michalski CW, Erkan M, Schuster T, Rosenberg R, Kleeff J, et al. Systematic review and meta-analysis of the role of defunctioning stoma in low rectal cancer surgery. Ann Surg 2008;248:52-60.

23. Tan WS, Tang CL, Shi L, Eu KW. Meta-analysis of defunctioning stomas in low anterior resection for rectal cancer. Br J Surg 2009; 96:462-72.

24. Baxter NN, Rothenberger DA, Lowry AC. Measuring fecal incontinence. Dis Colon Rectum 2003;46:1591-605.

25. Bols EM, Hendriks HJ, Berghmans LC, Baeten CG, de Bie RA. Responsiveness and interpretability of incontinence severity scores and FIQL in patients with fecal incontinence: a secondary analysis from a randomized controlled trial. Int Urogynecol J 2013;24:469-78. 